\title{
CHROMOPLAST BIOGENESIS IN CHELIDONIUM MAJUS PETALS
}

\author{
TAtjana Prebeg, NiKola LJUbešIĆ, MERCEDES Wrischer \\ Department of Molecular Biology, Ruđer Bošković Institute \\ Bijenička cesta 54, 10002 Zagreb, Croatia \\ e-mail:prebeg@irb.hr
}

(Received: November 14, 2005. Accepted: January 5, 2006)

\begin{abstract}
The differentiation of chromoplasts, with special emphasis on the formation and the organisation of chromoplast fibrils, was followed in the petals of the greater celandine, Chelidonium majus L. Electron microscopic observations showed that, in the epidermis, differentiation of chromoplasts started from leucoplasts, while mesophyll chromoplasts originated from chloroplasts. During petal maturation, fibrils accumulated in the plastids, often arranging in a parallel fashion to form compact birefringent bundles. Immediately before flower opening, these fibrillar bundles started to disorganise, and, at anthesis, most chromoplasts contained widely spaced fibrils which were irregularly dispersed through the plastid interior. During chromoplast differentiation, fibrils were commonly observed to protrude from plastoglobules, suggesting the possible site of their formation. Western analysis indicated that a protein antigenically related to fibrillin from pepper chromoplasts participates in the constitution of fibrils in Chelidonium petals.
\end{abstract}

KEY WORDS: Chelidonium majus L., greater celandine, chromoplast ultrastructure, chromoplast fibrils, fibrillin.

\section{INTRODUCTION}

Chromoplasts represent the most heterogeneous group of plastids considering the diversity of specific structures which bear the carotenoid pigments. The latter may deposit in the form of crystals, or accumulate in distinct lipoprotein structures which are commonly classified into three principal types - globules, membranes and fibrils (Sitte et al. 1980; Ljubešić et al. 1991).

In chromoplasts of the fibrillar type, the carotenoids are located in elongated, thread-like structures (mostly 15-40 $\mathrm{nm}$ in diameter), termed fibrils or tubules (Sitte et al. 1980; Ljubešić et al. 1991). These structures are often present in great abundance and tend to pack in a parallel fashion, thus forming long, compact bundles which appear as birefringent areas under the polarising microscope (Sitte et al. 1980). Biochemical and structural investigations indicated that the carotenoid molecules occupy the core of the fibrils and are surrounded by a sheath composed of lipids and proteins (Winkenbach et al. 1976; Knoth et al. 1986; Deruère et al. 1994; Vishnevetsky et al. 1999). Protein analyses in several plant species showed that the most abundant is a 30-35 kDa component (Winkenbach et al. 1976; Wuttke 1976; Knoth et al. 1986; Emter et al. 1990; Ljubešić et al. 1996; Wrischer et al. 1999). In pepper fruit, this protein was identified as a 32-kDa polypeptide and was designated fibrillin (also termed ChrB and PAP) (Newman et al. 1989; Deruère et al. 1994; Pozueta-Romero et al. 1997). It was suggested that fibrillin is the main component of the protein layer which acts as a shield around the layer of polar lipids, but also defines the shape of fibrils (Deruère et al. 1994).

The process of chromoplast differentiation comprises complex changes at the biochemical and structural levels. It is characterised by extensive accumulation of carotenoid pigments which is closely coordinated with the formation of specific carotenoid-bearing structures. However, the mechanisms underlying the structural changes involved in the morphogenesis of chromoplast substructures are still poorly understood. Here we examine the mode of differentiation of fibrillar type chromoplasts in the petals of the greater celandine, Chelidonium majus L. Special attention was given to the morphogenesis of fibrils as well as their organisation during chromoplast differentiation.

\section{MATERIALS AND METHODS}

\section{Plant material}

Experiments were performed on the petals of the greater celandine, Chelidonium majus L., growing in the Botanical Garden of the Faculty of Pharmacy and Biochemistry, University of Zagreb. 
For morphological studies, petals of Chelidonium majus L. in several stages of flower development were used: flower bud (4 $\mathrm{mm}$ in size) with greenish-white petals, flower buds $(6 \mathrm{~mm}, 8 \mathrm{~mm}$ and $10 \mathrm{~mm}$ in size) with yellow petals and open flower.

\section{Light and electron microscopies}

For detection of parallel arrays of fibrils in petal chromoplasts, hand made sections of fresh tissue were examined in differential interference contrast using a Zeiss Axiovert 35 microscope.

For ultrastructural analyses, small pieces of petal tissue were fixed for $20 \mathrm{~min}$ in $1 \%$ glutaraldehyde in $0.05 \mathrm{M}$ cacodylate buffer ( $\mathrm{pH}$ 7.2), and postfixed for $1 \mathrm{~h}$ in $1 \% \mathrm{OsO}_{4}$. After dehydration in a graded series of ethanol, the tissue was embedded in Araldite. Ultrathin sections were stained with uranyl acetate and lead citrate. For negative staining, the petal tissue was ground in a mortar adding a few drops of distilled water. Coarse fragments of tissue were separated by decanting. The cell components remaining in the supernatant were treated with $2 \%$ phosphotungstic acid. Ultrathin sections and negatively stained specimens were examined using a Zeiss EM10A electron microscope.

\section{Protein and immunological analyses}

The petal tissue was ground in a solution for protein denaturation $(60 \mathrm{mM}$ Tris- $\mathrm{HCl} \mathrm{pH} 6.8,25 \%$ glycerol, $2 \%$ sodium dodecyl sulphate, $14.4 \mathrm{mM}$ 2-mercaptoethanol, $0.1 \%$ bromphenol blue) with addition of polyvinylpyrolidone, and centrifuged at $10000 \mathrm{~g}$ for $15 \mathrm{~min}$. The proteins in the supernatant were denatured for $5 \mathrm{~min}$ at $80^{\circ} \mathrm{C}$, separated using $12.5 \%$ SDS-PAGE and visualised by staining with Coomassie brilliant blue R-250. Fibrillin was detected by Western blot analysis (according to a protocol given by Fulgosi et al. 1998) using antibodies (diluted 1:2000) raised in rabbits against pepper fibrillin. The antibodies were kindly provided by Dr. Bilal Camara, Institut de Biologie Moléculaire des Plantes du Centre National de la Recherche Scientifique et Université Louis Pasteur, Strasbourg, France. Bound antibodies were detected by an anti-rabbit $\mathrm{IgG}$ alkaline phosphatase conjugate. The membrane was developed with $0.56 \mathrm{mM}$ 5-bromo-4-chloro-3-indolyl phosphate (BCIP) plus $0.48 \mathrm{mM}$ nitro blue tetrazolium (NBT) in Tris buffer ( $\mathrm{pH}$ 9.6). Chromoplasts from pepper fruit were isolated according to Camara (1993) and used as a control in Western blot analysis.

\section{RESULTS}

\section{Chromoplast development in epidermal cells}

The epidermal cells of young petals contained leucoplasts with a few, often swollen, membranous sacks and a small number of plastoglobules (Fig. 1). The stroma of these plastids was dense and contained a considerable number of ribosomes.

Upon further flower bud development, leucoplasts progressively differentiated into chromoplasts. Fibrils accumulated throughout the plastid stroma and, as their number increased, they tended to arrange in parallel arrays (Fig. 2A). The fibrils which were observed close to the plastid envelope often appeared as being attached to it (Figs 2B, 3 ). Some fibrils protruded from small plastoglobules (30$60 \mathrm{~nm}$ in diameter) (Fig. 2C), which were scattered throughout the plastid interior. A transient feature in the early stages of chromoplast differentiation was the appearance of a tubular reticulum, which developed as a system of membranous, interconnecting tubules (40-130 $\mathrm{nm}$ in diameter) forming a network throughout the stroma (Fig. 3). The lumens of these tubules were often filled with rather osmiophilic granular material. The reticulum apparently originated by invagination of the inner membrane of the plastid envelope, as indicated by direct contacts between the reticulum and the envelope. In this stage of differentiation, the plastids also commonly contained 1-2 starch grains, which progressively vanished during further chromoplast development.

With the maturation of the flower buds, the plastid volume was almost completely occupied by fibrils, often being arranged in a parallel fashion to form long bundles (Fig. 4). When observed in differential interference contrast, most chromoplasts showed bright interiors, apparently due to the birefringence of parallelly arranged fibrils (Fig. 5). Negative staining of fibrils isolated from developing petals showed single fibrils along with spindle-shaped structures (Fig. 6). The latter reached $2.5 \mu \mathrm{m}$ in length and probably corresponded to the fibrillar bundles. In transverse sections, most fibrils were roundish (13-16 nm in diameter), but, rather frequently, structures which appeared to be formed of several incompletely separated fibrils were also present (Fig. 7). All forms of fibrils had darkly stained envelopes which enclosed their electron-translucent cores. Between neighbouring, closely packed, fibrils in the bundles darkly stained cross-bridges were occasionally observed (Fig. 7). At this stage of differentiation, many chro-

Figs 1-7. Differentiation of epidermal chromoplasts in Chelidonium majus petals.

Fig. 1. Transmission electron micrograph showing leucoplast with a few membranous sacks (m) and a small number of plastoglobules (arrowheads). Scale bar $=0.25 \mu \mathrm{m}$.

Fig. 2. A-C. Transmission electron micrographs showing early chromoplast biogenesis. A - immature chromoplast with accumulating fibrils. Scale bar $=$ $0.25 \mu \mathrm{m} . \mathrm{B}-$ part of plastid envelope with attached fibrils. Scale bar $=0.1 \mu \mathrm{m}$. C - fibril protruding from plastoglobule. Scale bar $=0.1 \mu \mathrm{m}$.

Fig. 3. Transmission electron micrograph showing a chromoplast with extensive tubular reticulum (arrowheads). Fibrils organised in parallel arrays are present in the stroma. Some fibrils are arranged along the plastid envelope (arrow). Scale bar $=0.25 \mu \mathrm{m}$.

Fig. 4. Transmission electron micrograph showing part of a chromoplast with a longitudinally sectioned fibrillar bundle (fb). Roundish inclusions (arrows) containing granular material are evident in the stroma. Scale bar $=0.25 \mu \mathrm{m}$.

Fig. 5. Differential interference contrast image showing epidermal chromoplasts with bright birefringent interiors. Scale bar $=10 \mu \mathrm{m}$.

Fig. 6. Transmission electron micrograph showing negatively-stained isolated fibrils. Single fibrils along with spindle-shaped structures which probably correspond to fibrillar bundles are seen. Scale bar $=0.25 \mu \mathrm{m}$.

Fig. 7. Transmission electron micrograph showing part of a chromoplast with cross-sectioned fibrillar bundle. Cross-bridges between neighbouring fibrils are evident at some places (arrows). Structures which appear to be composed of several incompletely separated fibrils can be seen (arrowheads). Scale bar $=0.1 \mu \mathrm{m}$ 

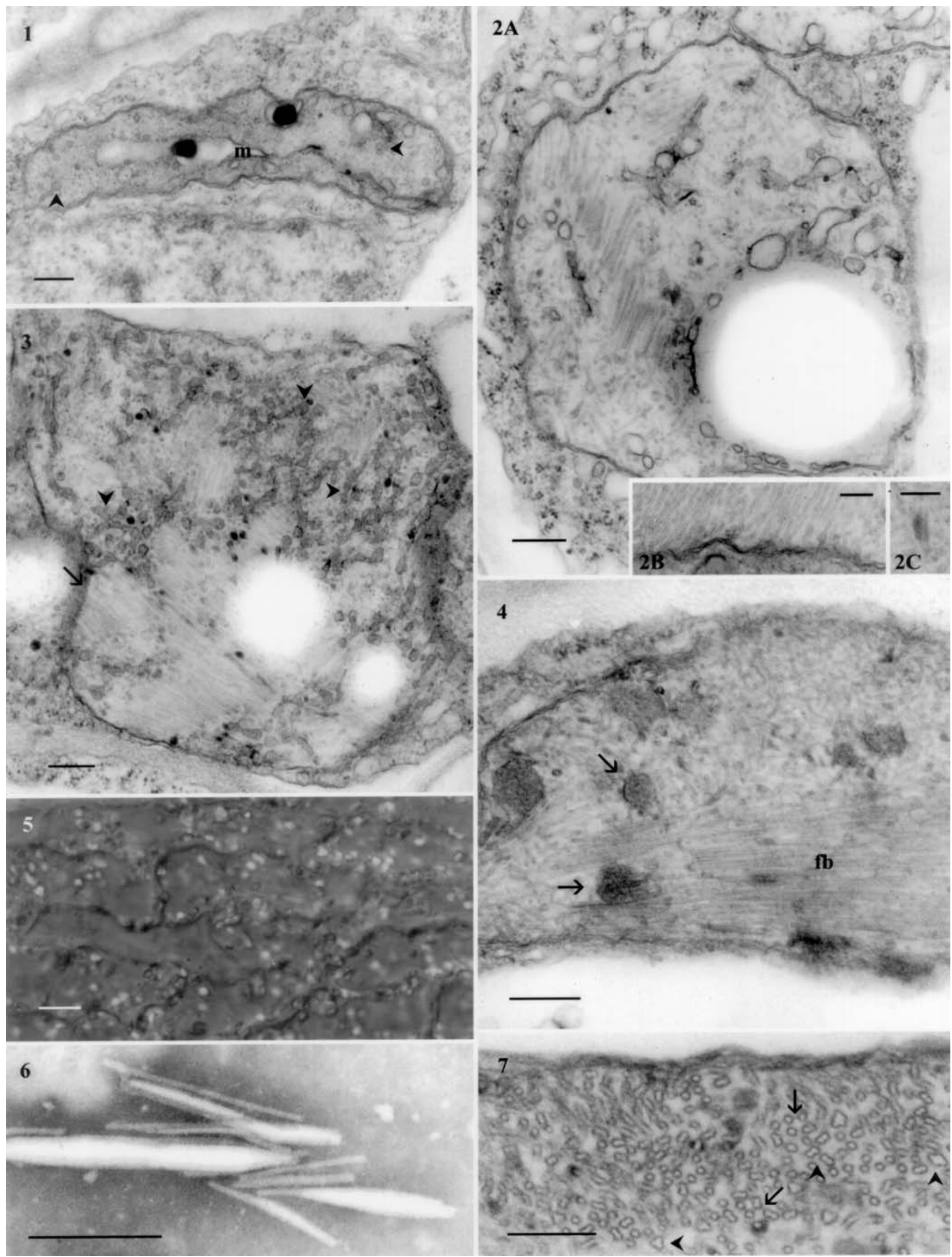
moplasts also contained several roundish osmiophilic inclusions (up to $0.5 \mu \mathrm{m}$ in diameter) which appeared to be enclosed by membranes (Fig. 4). Their interior was filled with granular electron-dense material, often resembling an accumulation of incompletely formed fibrils. These inclusions disappeared during further chromoplast development.

Immediately before anthesis, the fibrillar bundles started to disorganise and the fibrils dispersed through the entire chromoplast interior. Ribosomes were no longer detected and the stroma became lightly stained with homogeneous appearance.

At anthesis, the chromoplasts often appeared considerably enlarged and, in many cases, assumed irregular outlines, with amoeboid extensions protruding into the cytoplasm or vacuole (Fig. 8). Most fibrillar bundles were completely disassembled, loosing their birefringence (Figs 8, 9). In many chromoplasts, the fibrils became very widely spaced. The contact of the fibrils with the plastid envelope was still commonly observed in the peripheral stroma. The plastoglobules were relatively rare and occasionally found to be attached to the fibrils.

\section{Chromoplast development in mesophyll cells}

Mesophyll cells of young petals contained chloroplasts with a simple thylakoid system: it mostly consisted of single, or stacks of two thylakoids, but occasionally 3-4 thylakoids formed small grana (Fig. 10). These plastids had a dense stroma with abundant ribosomes, and usually contained a starch grain and a small number of plastoglobules.
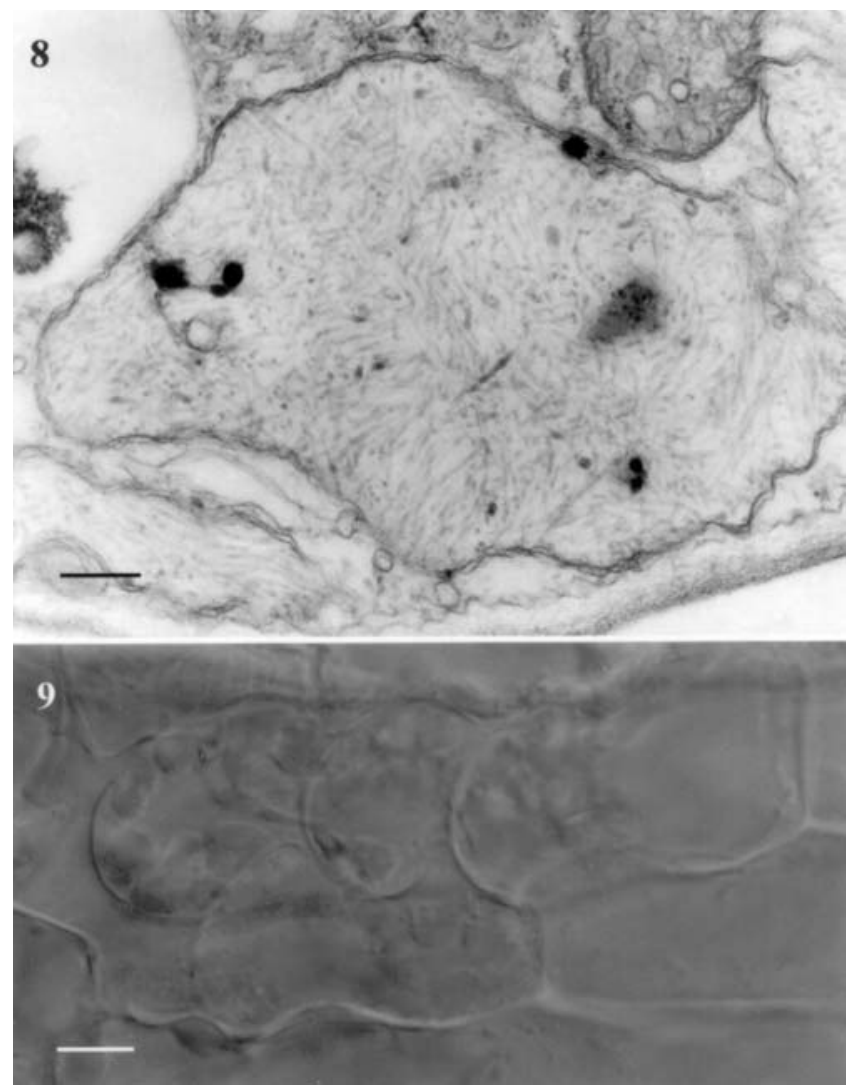

Figs 8-9. Epidermal chromoplasts in fully differentiated Chelidonium majus petals.

Fig. 8. Transmission electron micrograph showing chromoplast filled with scattered fibrils. Scale bar $=0.25 \mu \mathrm{m}$.

Fig. 9. Differential interference contrast image showing epidermal chromoplasts without birefringent interiors. Scale bar $=10 \mu \mathrm{m}$.
Upon further petal development, the chloroplasts differentiated into chromoplasts filled with fibrils (Fig. 11). The morphological characteristics of the fibrils, as well as their tendency to locate along the plastid envelope and to arrange in a parallel fashion, corresponded to the situation in epidermal plastids. Fibrils protruding from plastoglobules were also commonly found. Concomitantly with accumulation of the fibrils, the thylakoid system was progressively reduced, with membranes becoming dilated and wavy-shaped. During their early development, many chromoplasts also deposited large starch grains which, as their differentiation proceeded, gradually disappeared.

At anthesis, the thylakoid system was completely degraded. The plastid stroma was homogeneous and lightly stained, while ribosomes were no longer observed. The chromoplasts were occupied by dispersed fibrils, being morphologically very similar to the epidermal ones (Fig. 12).

\section{Protein and immunological analyses}

In order to examine whether proteins of the fibrillin family participate in the formation of fibrils in Chelidonium chromoplasts, immunological detection was performed. Proteins were extracted from whole petals at anthesis because the small amount of plant material available did not permit the preparation of isolated chromoplasts. SDS electrophoresis of the petal proteins revealed a band with a molecular mass of about $31 \mathrm{kDa}$ which migrated in close proximity to pepper fibrillin used as a standard (Fig. 13A). Western blot analysis indicated that this protein is immunologically related to fibrillin (Fig. 13B)

\section{DISCUSSION}

Ultrastructural studies showed that the main carotenoidbearing structures in chromoplasts of Chelidonium petals are fibrils. In a considerable number of species, chromoplast fibrils were observed to protrude from plastoglobules (Simpson and Lee 1976; Wuttke 1976; Ljubešić 1977; Simpson et al. 1977; Simpson et al. 1978; Knoth et al. 1986; Wrischer et al. 1999; Bonora et al. 2000), indicating the role of plastoglobules in the initial steps of fibril formation. It is generally considered that fibrils develop by selfassembling when all their three structural components (carotenoid pigments, lipids and proteins) are present (Emter et al. 1990; Deruère et al. 1994). In this process, the plastoglobules probably act as accumulation sites for fibril constituents and also create a favourable medium for their assembly. Fibril elongation from plastoglobules is especially pronounced in the chromoplasts of fruits, where the plastoglobules tend to be numerous and large, and, in some cases, are pierced by more than one fibril (Simpson and Lee 1976; Wuttke 1976; Ljubešić 1977; Simpson et al. 1977; Simpson et al. 1978; Knoth et al. 1986). In flower chromoplasts, the role of plastoglobules in the formation of fibrils has been proposed for Strelitzia reginae (Simpson et al. 1975) and Impatiens noli-tangere (Wrischer et al. 1999). However, in a number of flowers studied thus far, the plastoglobules were not found to participate in the fibril morphogenesis (Smith and Butler 1971; Falk 1976; Ljubešić et al. 1995; Ljubešić et al. 1996), implicating that the plastoglobules are not a necessary prerequisite for fibril formation. In the Chelidonium petals, fibrils protruding from pla- 


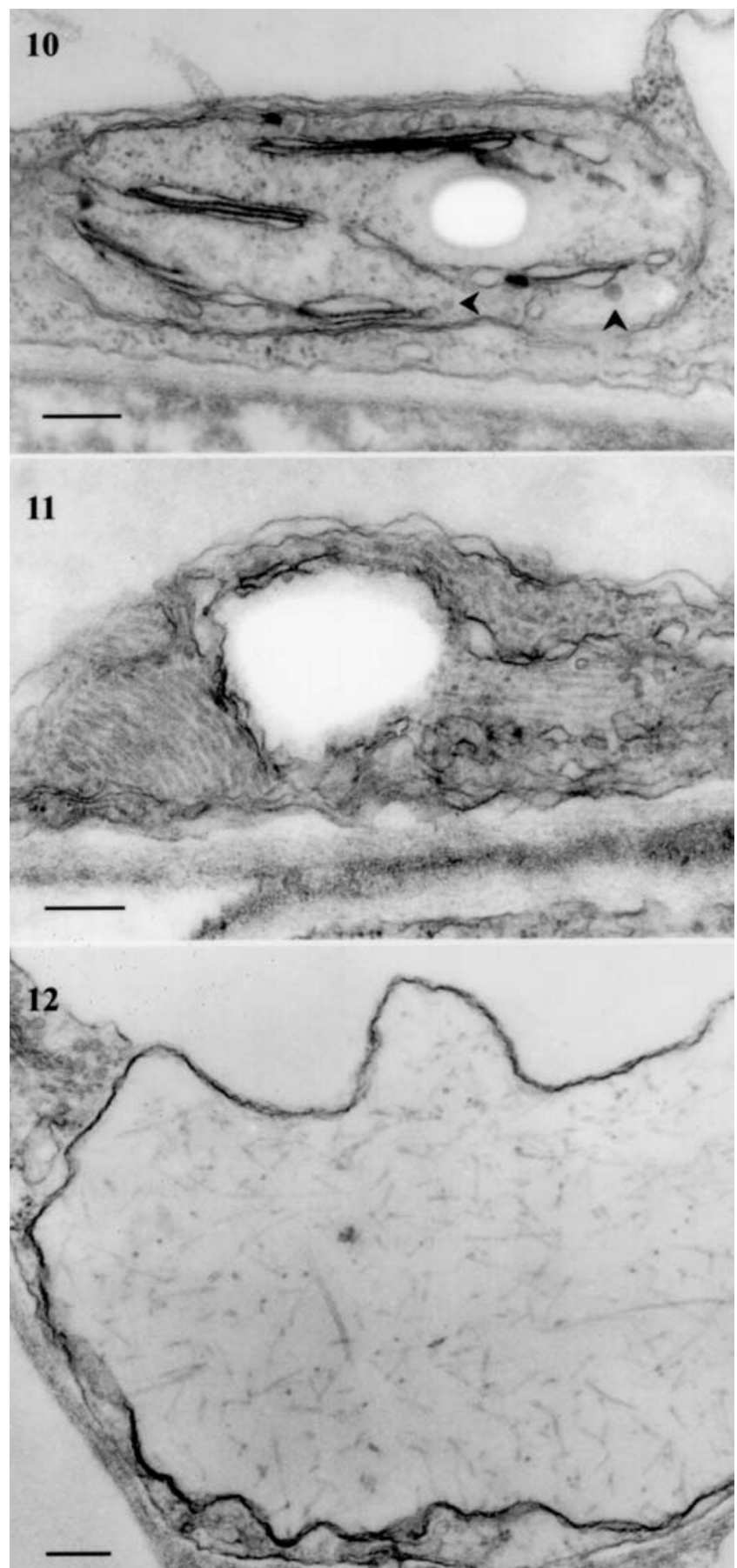

Figs 10-12. Transmission electron micrographs showing differentiation of mesophyll chromoplasts in Chelidonium majus petals.

Fig. 10. Chloroplast with a simple thylakoid system. A few plastoglobules are seen in the stroma (arrowheads). Scale bar $=0.25 \mu \mathrm{m}$.

Fig. 11. Chromoplast with parallelly arranged fibrils. Degenerating thylakoid membranes and a starch grain are evident. Scale bar $=0.25 \mu \mathrm{m}$.

Fig. 12. Chromoplast with dispersed fibrils. Scale bar $=0.25 \mu \mathrm{m}$.

stoglobules were commonly found during chromoplast differentiation. However, the number of plastoglobules was relatively low, indicating that they only partially contribute to the formation of fibrils.

In Chelidonium chromoplasts, contact of fibrils with the inner membrane of the plastid envelope was commonly observed. This feature was also reported for flower chromoplasts of several other species (Ljubešić et al. 1995; Wrischer et al. 1999). Such ultrastructural observations lead to the question: do the fibrils simply have a tendency toward

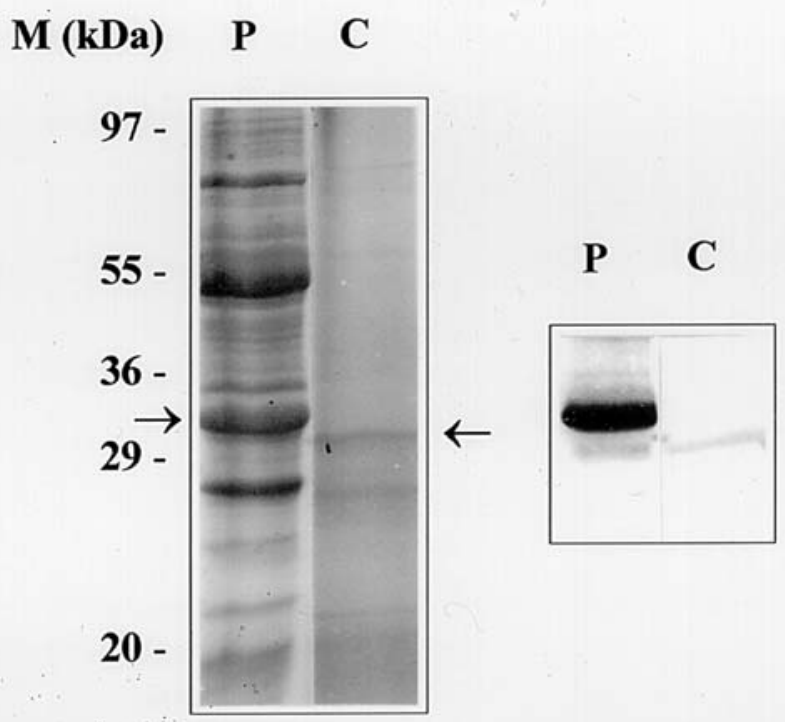

A

B

Fig. 13. Detection of a protein immunologically related to fibrillin, in Chelidonium petals. A - protein analysis; $\mathrm{B}-$ Western blot analysis. $\mathrm{M}-$ marker proteins, $\mathrm{P}$ - proteins from pepper chromoplasts; $\mathrm{C}$ - total proteins from Chelidonium petals. The arrows indicate the bands corresponding to fibrillin.

attachment to membranes or are the plastid membranes in some way involved in their formation. It can be speculated that membranes could act in incipient steps of fibril assembly as some kind of anchor for fibril constituents, thus facilitating their formation.

Before the most intense formation of fibrils, a transient structure appeared in the chromoplasts of Chelidonium: the tubular reticulum. It is considered to be a rarely found, specific type of chromoplast internal membrane which is probably derived, by invagination, from the inner membrane of the plastid envelope (Ljubešić et al. 1991). Although the tubular reticulum is found very rarely as a dominant chromoplast structure (Schnepf and Czygan 1966; Ljubešić 1979), its transient presence has been described during the maturation of fibrillar chromoplasts in the flowers of Tropaeolum majus and Thunbergia alata (Falk 1976; Ljubešić et al. 1996). The possible roles of this structure in chromoplast development and in the formation of carotenoid-bearing structures are not clear. Since the tubular reticulum forms a discrete plastid subcompartment, it appears likely that it could be involved in the synthesis or accumulation of some plastid components.

Deruère et al. (1994) showed that the presence of the protein, fibrillin, is necessary for fibril formation in pepper chromoplasts and fibrillin-type proteins were also detected in the chromoplasts in the flowers of Tropaeolum majus and Cucurbita maxima. Similarly, a protein homologous to fibrillin, CHRC, was characterised in fibrillar type chromoplasts of Cucumis sativus corollas (Smirra et al. 1993; Vishnevetsky et al. 1996). Here we found the presence of a protein immunologically related to fibrillin in the chromoplasts of Chelidonium majus, corroborating the ubiquitous presence of proteins belonging to the fibrillin family in chromoplast fibrils. It is generally believed that the role of fibrillin proteins in chromoplasts is structural, i.e. that 
they stabilise specific carotenoid-bearing structures thus preventing harmful effects of excessive carotenoid accumulation (Deruère et al. 1994; Vishnevetsky et al. 1999).

The greatest compactness of fibrillar arrangement in Chelidonium chromoplasts was attained while the petals were still enclosed in the flower bud. The fibrils were often organised into bundles and some closely packed neighbouring fibrils were observed to be connected by darkly stained cross-bridges, a feature also described for the chromoplasts of Tropaeolum majus flowers (Falk 1976) and $\mathrm{Ca}$ psicum annuum fruit (Deruère et al. 1994). Analysis of the fibrillin amino acid sequence suggests the presence of a domain which could be responsible for building these connections (Deruère et al. 1994). Immediately before anthesis, the bundles started to disorganise in the Chelidonium chromoplasts, and in open flowers most fibrils were randomly dispersed throughout the stroma. Concomitantly with bundle disintegration, the ribosomes vanished and the stroma appeared „empty”. Similar developmental patterns were previously reported for fibrillar type chromoplasts of flowers at anthesis, in some other plant species (Smith and Butler 1971; Falk 1976; Wrischer et al. 1999). Such ultrastructural features of chromoplasts generally resemble the process of senescence. However, it appears more appropriate to consider it the last stage of chromoplast differentiation, since, at least from an ecological point of view, the function of chromoplasts is fulfilled in open flowers.

\section{ACKNOWLEDGEMENTS}

The authors thank Dr. Bilal Camara for generously providing antibodies against pepper fibrillin and Dr. Volker Magnus for critical reading of the manuscript.

\section{LITERATURE CITED}

BONORA A., PANCALDI S., GUALANDRI R., FASULO M.P. 2000. Carotenoid and ultrastructure variations in plastids of Arum italicum Miller fruit during maturation and ripening. J. Exp. Bot. 51: 873-884.

CAMARA B. 1993. Plant phytoene synthase complex: component enzymes, immunology, and biogenesis. Method. Enzymol. 214: 352-365.

DERUÈRE J., RÖMER S., D'HARLINGUE A., BACKHAUS R.A., KUNTZ M., CAMARA B. 1994. Fibril assembly and carotenoid overaccumulation in chromoplasts: a model for supramolecular lipoprotein structures. Plant Cell 6: 119-133.

EMTER O., FALK H., SITTE P. 1990. Specific carotenoids and proteins as prerequisites for chromoplast tubule formation. Protoplasma 157: 128-135.

FALK H. 1976. Chromoplasts of Tropaeolum majus L.: structure and development. Planta 128: 15-22.

FULGOSI H., VENER A.V., ALTSCHMIED L., HERRMANN R.G., ANDERSSON B. 1998. A novel multi-functional chloroplast protein: identification of a $40 \mathrm{kDa}$ immunophilin-like protein located in the thylakoid lumen. EMBO J. 17: 1577$-1587$.

KNOTH R., HANSMANN P., SITTE P. 1986. Chromoplasts of Palisota barteri, and the molecular structure of chromoplast tubules. Planta 168: 167-174.
LJUBEŠIĆ N. 1977. The formation of chromoplasts in fruits of Cucurbita maxima Duch. 'turbaniformis'. Bot. Gaz. 138: 286$-290$.

LJUBEŠIĆ N. 1979. Chromoplasts in the petals of Liriodendron tulipifera L. Z. Pflanzenphysiol. 91: 49-52.

LJUBEŠIĆ N., WRISCHER M., DEVIDÉ Z. 1991. Chromoplasts - the last stages in plastid development. Int. J. Dev. Biol. 35: 251-258.

LJUBEŠIĆ N., WRISCHER M., DEVIDÉ Z. 1995. Development of chromoplast tubules in Hypericum flowers. Period. Biol. 97: 333-336.

LJUBEŠIĆ N., WRISCHER M., DEVIDÉ Z. 1996. Chromoplast structures in Thunbergia flowers. Protoplasma 193: 174-180.

NEWMAN L.A., HADJEB N., PRICE C.A. 1989. Synthesis of two chromoplast-specific proteins during fruit development in Capsicum annuum. Plant Physiol. 91: 455-458.

POZUETA-ROMERO J., RAFIA F., HOULNÉ G., CHENICLET C., CARDE J.P., SCHANTZ M.L., SCHANTZ R. 1997. A ubiquitous plant housekeeping gene, PAP, encodes a major protein component of bell pepper chromoplasts. Plant Physiol. 115: 1185-1194.

SCHNEPF E., CZYGAN F.C. 1966. Feinbau und Carotinoide von Chromoplasten im Spadix-Appendix von Typhonium und Arum. Z. Pflanzenphysiol. 54: 345-355.

SIMPSON D.J., BAQAR M.R., LEE T.H. 1975. Ultrastructure and carotenoid composition of chromoplasts of the sepals of Strelitzia reginae Aiton during floral development. Ann. Bot. 39: $175-183$.

SIMPSON D.J., BAQAR M.R., LEE T.H. 1977. Fine structure and carotenoid composition of the fibrillar chromoplasts of Asparagus officinalis L. Ann. Bot. 41: 1101-1108.

SIMPSON D.J., BAQAR M.R., LEE T.H. 1978. Chromoplast ultrastructure in fruit of Solanum pseudocapsicum and fruit and sepals of Physalis alkekengi. Aust. J. Bot. 26: 793-806.

SIMPSON D.J., LEE T.H. 1976. The fine structure and formation of fibrils of Capsicum annuum L. chromoplasts. Z. Pflanzenphysiol. 77: 127-138.

SITTE P., FALK H., LIEDVOGEL B. 1980. Chromoplasts. In: F.C. Czygan (ed.) Pigments in plants. 2nd edn. Stuttgart, New York: G. Fischer.

SMIRRA I., HALEVY A., VAINSTEIN A. 1993. Isolation and characterization of a chromoplast-specific carotenoid-associated protein from Cucumis sativus corollas. Plant Physiol. 102: 491-496.

SMITH M., BUTLER R.D. 1971. Ultrastructural aspects of petal development in Cucumis sativus with particular reference to the chromoplasts. Protoplasma 73: 1-13.

VISHNEVETSKY M., OVADIS M., ITZHAKI H., LEVY M., LIBAL-WEKSLER Y., ADAM Z., VAINSTEIN A. 1996. Molecular cloning of a carotenoid-associated protein from $\mathrm{Cu}$ cumis sativus corollas: homologous genes involved in carotenoid sequestration in chromoplasts. Plant J. 10: 1111-1118.

VISHNEVETSKY M., OVADIS M., VAINSTEIN A. 1999. Carotenoid sequestration in plants: the role of carotenoid-associated proteins. Trends Plant Sci. 4: 232-235.

WINKENBACH F., FALK H., LIEDVOGEL B., SITTE P. 1976. Chromoplasts of Tropaeolum majus L.: Isolation and characterization of lipoprotein elements. Planta 128: 23-28.

WRISCHER M., LJUBEŠIĆ N., PREBEG T., MAGNUS V. 1999. The succession of chromoplast structures in Impatiens noli-tangere flowers. Phyton (Horn, Austria) 39, 49-59.

WUTTKE H.G. 1976. Chromoplasts in Rosa rugosa: development and chemical characterization of tubular elements. Z. Naturforsch. 31c, 456-460. 